\title{
ANÁLISE ECONÔMICA DE OFERTA E DEMANDA DO ABACATE NA ALTA PAULISTA
}

Fernando Ferrari Putti ${ }^{1}$

Bruno César Góes ${ }^{2}$

Pedro Fernando Cataneo ${ }^{3}$

\section{RESUMO}

O objetivo deste trabalho, visa analisar a oferta e demanda de abacate no Brasil, identificando os estados produtores e onde está concentrada a sua produção; a demanda brasileira de consumo do fruto em relação ao mundo, informando os benefícios nutricionais do abacate, no combate e prevenção doenças cardiovasculares, entre outras; e tendo como foco de estudo, a produção na região da alta paulista. Foram feitos levantamento de dados através de pesquisas com base no Escritório de Desenvolvimento Regional de Tupã (EDR) e do Instituto de Economia Agrícola (IEA).

PALAVRAS-CHAVE: Exportação, consumo, mercado.

\section{ECONOMIC ANALYSIS OF SUPPL AND DEMAND OF AVOCADO PAULO ON HIGH}

\footnotetext{
1 Mestre e Doutorando em Agronomia, Univ Estadual Paulista - Campus de Botucatu. fernandoputti@fca.unesp.br

Graduando em Administração, Univ Estadual Paulista - Campus de Tupã. brunocgoes@tupa.unesp.br

${ }^{3}$ Mestre e Doutor em Agronomia, Univ Estadual Paulista - Campus de Tupã. pedro@tupa.unesp.br
} 


\begin{abstract}
This study aims to analyze the supply of avocado in Brazil, identifying the producing states and where their production is concentrated; Brazilian demand consumption of the fruit in relation to the world, stating the nutritional benefits of avocados, in combating and preventing cardiovascular diseases, among others; and focusing the study on the production of high Paulista region. Survey data were made through research based in the Office of Regional Development Tupa (EDR) and the Institute of Agricultural Economics (IEA).
\end{abstract}

KEY-WORDS: Export.Consumption. Market.

\title{
ANÁLISIS E ECONÔMICO DE LA OFERTA Y LA DEMANDA DE AGUACATE PAULO EM ALTA
}

\section{RESUMEN}

Este estudio tiene como objetivo analizar la oferta de palta en Brasil, la identificación de los estados productores y en los que su producción se concentra; el consumo de la demanda brasileña de la fruta en relación con el mundo, exponiendo los beneficios nutricionales de los aguacates, en la lucha y prevención de las enfermedades cardiovasculares, entre otras; y se centra el estudio en la producción de alta región Paulista. Los datos de encuestas se realizaron a través de la investigación basada en la Oficina de Desarrollo Tupa Regional (EDR) y el Instituto de Economía Agrícola (IEA).

PALABRAS-CLAVE Exportación. El consumo. El mercado.

\section{INTRODUÇÃO}

O abacate tem sua origem no continente americano, mais especificamente no México. Sendo uma fruta com alto valor proteico e vitamínico. A produção mundial de abacate, de acordo com FAO (2014) cresceu 19\% no período entre 2006 e 2012, chegando a 4 milhões de toneladas. O México é o maior produtor do fruto, responsável por 33\%, seguido pela Indonésia, Republica Dominicana, Estados Unidos, Colômbia, Peru, Quênia, Chile, Brasil e Ruanda, sendo esses dez primeiros lugares responsável por um total de $81 \%$ da produção mundial.

No entanto a produção de abacate no Brasil vem sofrendo constantes quedas, que era de 474.538 toneladas em 1990 passando para 159.903 toneladas em 2012. Em nível nacional, São Paulo se faz importante na produção da fruta, por ser o maior produtor e por abrigar mão-de-obra necessária para essa cultura. Sendo responsável por um total de 52\%, seguido de Minas Gerais com 23\% e Paraná 10\%. 
(FRANCISCO; BAPTISTELLA, 2005).

Essa queda na produção pode ser atribuída ao fato dos produtores procurarem culturas de maior rentabilidade, pelo hábito brasileiro de consumi-lá apenas como sobremesa, batida com açúcar e leite, o que acaba sendo baixo o seu consumo, limitando desse modo a sua expansão.

No entanto, o Brasil possui condições edafoclimáticas favoráveis para a cultura do abacateiro, sendo de grande influência, a temperatura e a precipitação. Onde para o seu cultivo, desaconselha-se regiões onde ocorrem quedas frequentes de temperaturas no inverno, principalmente abaixo de $-3{ }^{\circ} \mathrm{C}$, ou no verão, elevação superior a $40{ }^{\circ} \mathrm{C}$, com frequência. Deve-se evitar também período de estiagem prolongadas, principalmente no verão, causando a queda de folhas prejudicando dessa maneira a produtividade do abacateiro. Já também o excesso de precipitação, causa queda da produção assim como a qualidade dos frutos. (TEIXEIRA, 1991).

Porém, pesquisas realizadas sobre os benefícios do abacate, revelam o seu efeito na redução dos níveis de colesterol ruim (HDL), colesterol total e triglicérides, além do efeito de controle da glicemia em pessoas com diabetes.

O objetivo do presente trabalho visa analisar a oferta e demanda da produção de abacate do Brasil, e focando a produção na Alta Paulista.

\section{DESENVOLVIMENTO}

\section{RESULTADOS E DISCUSSÕES}

Este produto é considerado um bem de consumo não durável, ou seja, para ser consumido imediatamente, caso típico dos alimentos, principalmente das frutas, que possuem um tempo mais acelerado para sua degradação.

A delimitação geográfica de estudo foi toda a região de Tupã, bem como os estados de Belém do Pará, Rio de Janeiro, São Paulo, Fortaleza e principalmente exportação para o mercado europeu (França) e África do Sul. Este trabalho visou estudar o Escritório de Desenvolvimento Regional (EDR) de Tupã e mercado europeu. 
Para estudo da oferta e demanda de abacates no mercado delimitado foram utilizadas séries históricas de variáveis de: perfil do consumidor de ambos mercados, consumo regional, nacional e mundial de abacate, consumo do mercado.

\subsection{Estudo da Oferta}

Ao realizar a análise do mercado da produção de abacate no mundo, nota-se que o México destaca- se, seguida pelo Chile. Assim, a produção se encontra em regiões de clima temperado, e países em desenvolvimento. Sendo que o maior foco dos produtores está voltado para a exportação.

Figura 1: Principais produtores de abacate do mundo

\begin{tabular}{|l|r|}
\hline \multicolumn{2}{|c|}{ Principais produtores de abacate do mundo } \\
\hline $1^{\mathrm{a}}$ Mexico & volume $(\mathrm{cx})$ \\
\hline $2^{\mathrm{a}}$ Chile & 51.116 .591 \\
\hline $3^{\mathrm{a}}$ Rep. Dominicana & 11.363 .636 \\
\hline $4^{\mathrm{a}}$ Colombia & 8.518 .091 \\
\hline $5^{\mathrm{a}}$ Brasil & 8.362 .181 \\
\hline $6^{\mathrm{a}}$ Peru & 7.545 .454 \\
\hline $7^{\mathrm{a}}$ Espanha & 5.532 .727 \\
\hline $8^{\mathrm{a}}$ EUA & 5.454 .545 \\
\hline $9^{\mathrm{a}}$ Guatemala & 5.195 .681 \\
\hline $10^{\mathrm{a}}$ China & 4.387 .500 \\
\hline
\end{tabular}

Fonte: FOB, 2010.

Podemos notar, que mesmo a produção do Brasil ocupa uma posição dentre os dez maiores produtores de abacate do mundo, com um total de 7.545 .454 caixas por ano.

Essa participação no mercado mundial de abacate ocupada pelo Brasil, ainda é considerado muito limitada, devido a falta de produtividade e da qualidade dos frutos, ocasionados pela falta de condições adequadas do seu manejo, como também problemas de logísticas encontrado ao longo da cadeia produtiva, e da falta de apoio governamental de incentivo a pesquisa e desenvolvimento, não possuindo uma política nacional de incentivo a expansão da cultura do abacate. 
Figura 2: Produção brasileira de abacate (cxs) em 2010 e linha de tendência

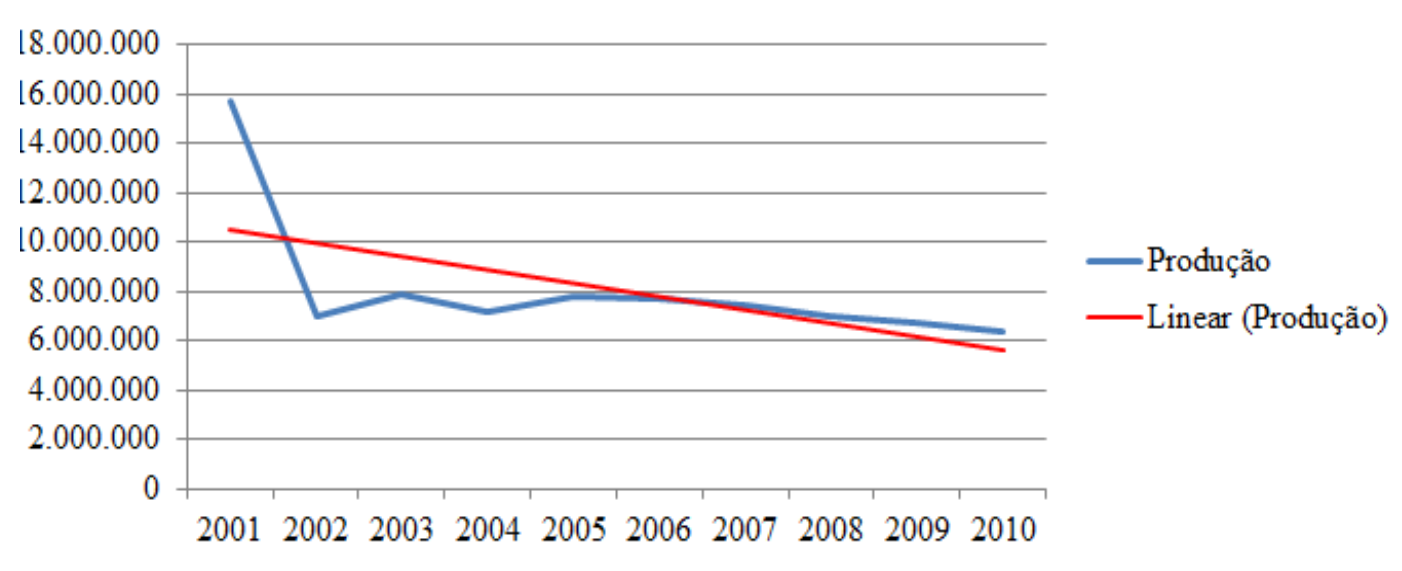

Fonte: IBGE, 2010.

Dentre do estado de São Paulo observa-se que a tendência dos últimos anos é no aumento da produção. Sendo que mesmo com o advento da cana de açúcar, ainda vem ocorrendo o aumento, esse fato pode se oriundo da inserção de tecnologia, assim como a preocupação com os tratos culturais.

Figura 3: Produção de abacate no estado de São Paulo

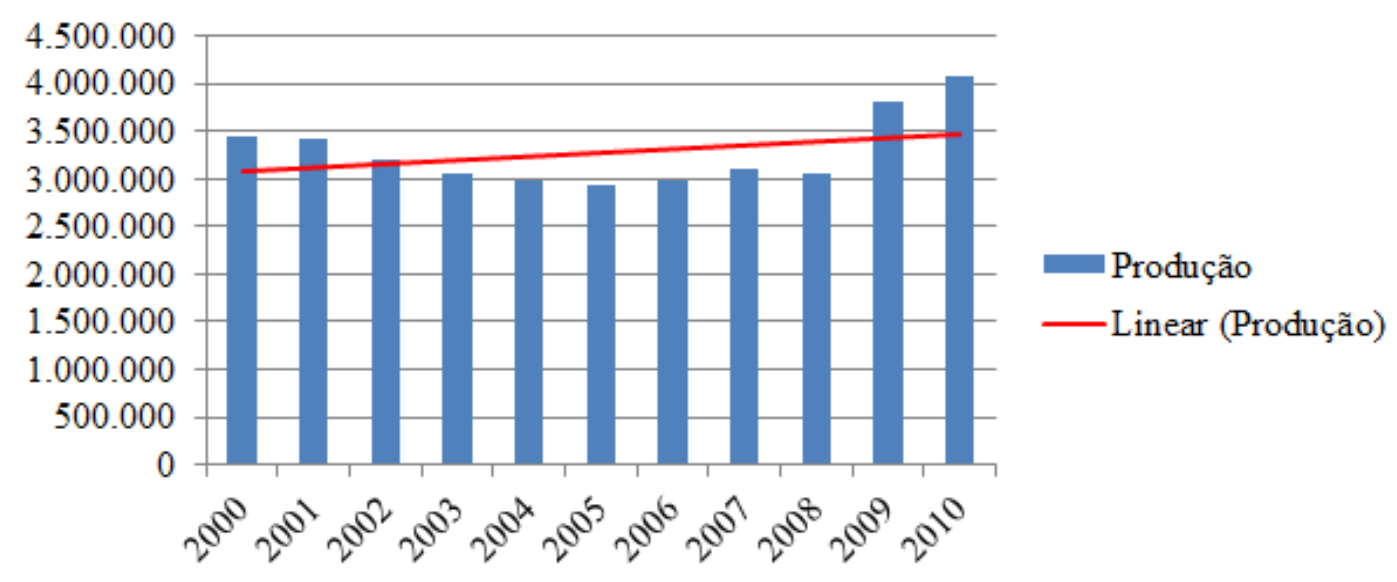

Fonte: IEA, 2010. 
Em contramão a produtividade nacional, a produção do abacateiro no Estado de São Paulo vem em ritmo de crescimento conforme a figura 3, representando $53,9 \%$ da produção nacional, onde $75 \%$ da produção do Estado de São Paulo, concentra-se em 39 munícipios, sendo destaque para Mogi-Mirim, Jardinópolis, Bauru, Santo Antônio da Posse, Araras e Tupã.

Figura 4: Preço da caixa de abacate no estado de São Paulo

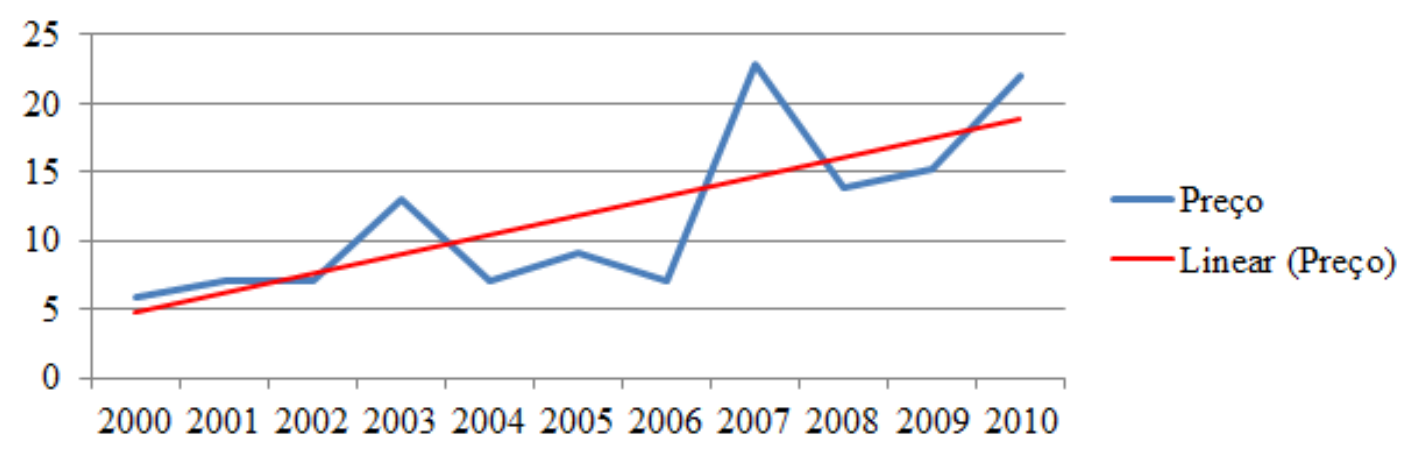

Fonte: IEA, 2010.

Por meio da observação do gráfico de preço do abacate no estado de São Paulo, observamos que está havendo um crescimento gradativo, com picos nos anos de 2003 e 2007, motivados principalmente pelo declínio da produção e o aumento de consumo da fruta.

O mercado base de nossa análise será o delimitado pelo Escritório de Desenvolvimento Regional (EDR) de Tupã, os quais são participantes as cidades: Arco-Íris, Bastos, Herculândia, lacri, Inúbia Paulista, Lucélia, Osvaldo Cruz, Parapuã, Pracinha, Queiroz, Rinópolis, Sagres, Salmourão e Tupã. No gráfico a seguir, podemos analisar cronologicamente a partir de 2000 a produção de abacate no EDR de Tupã, segundo o Instituto de Economia Agrícola (IEA).

Figura 5: Produção de abacate no EDR de Tupã 


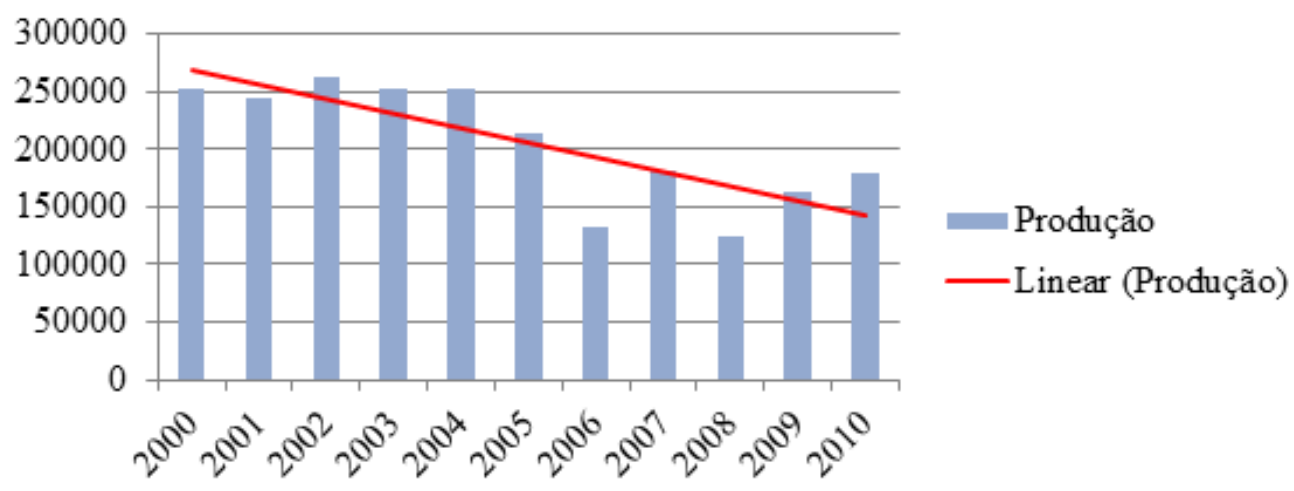

Fonte: IEA, 2010.

Observamos que em 2006, com a atratividade da indústria canavieira, tanto para produção, quanto para arrendamento de terra, houve um decréscimo produtivo da cultura do abacate. O gráfico ainda apresenta uma linha de tendência, a qual projeta um cenário de queda produtiva, o que pode estar relacionado com a estagnação do consumo e o fortalecimento da cultura canavieira e do amendoim (CATI, 2011).

Em 2010 os números produtivos dessa região foram de 178.310 caixas de 22 $\mathrm{kg}$, separados nas quatro cidades produtivas da região, conforme o gráfico de produção de abacate nas cidades do EDR de Tupã:

Figura 6: Produção de abacate nas cidades do EDR de Tupã em 2010

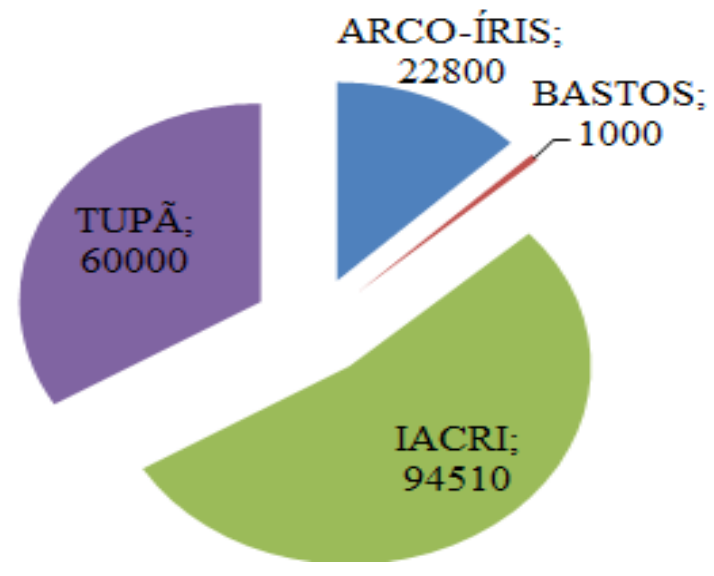

Fonte: IEA/CATI - SAAESP. 
Figura 7: Volume de exportação de abacate

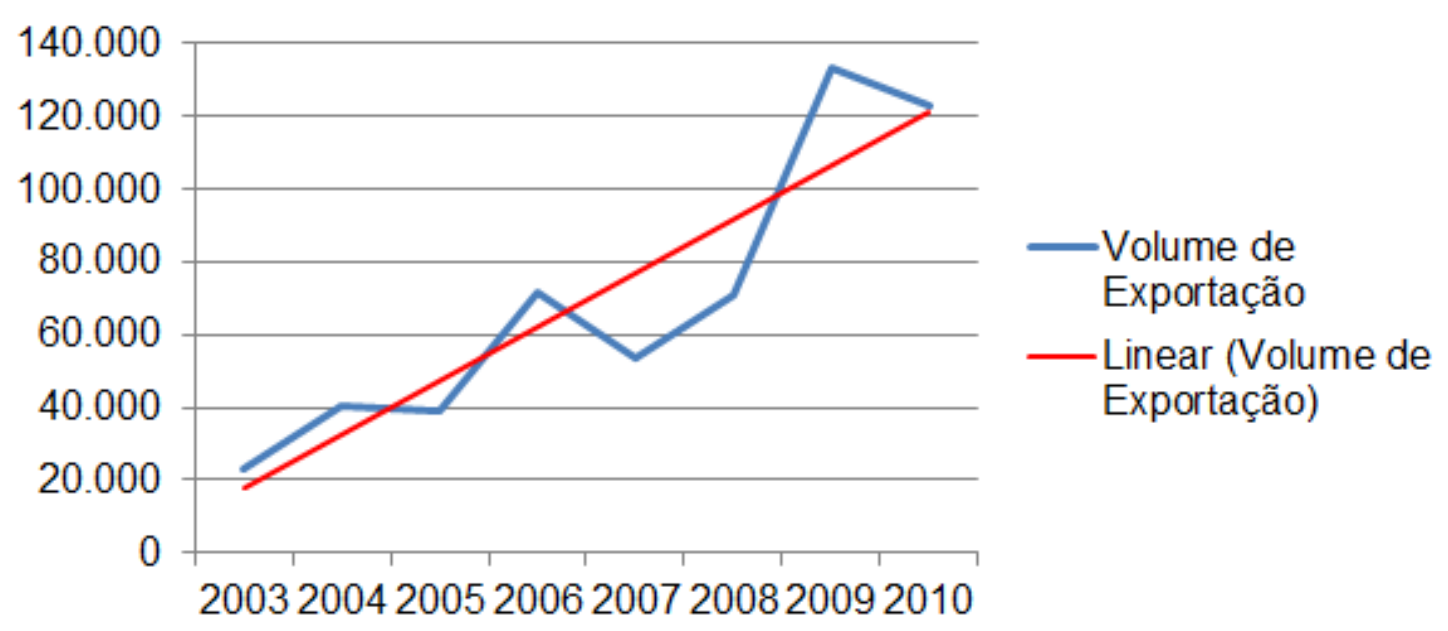

Fonte: IBRAF, 2010.

\subsection{Estudo da Demanda}

O consumo de frutas no Brasil é relativamente baixo, segundo o Instituto Brasileiro de Fruticultura (IBRAF), o consumo per capita de frutas no Brasil é de apenas $57 \mathrm{Kg}$ por ano, bem abaixo de países europeus, como Itália (114 Kg/ano) e Espanha (120 Kg/ano).

No caso do abacate, o consumo no Brasil fica em torno de 301 gramas/hab. ano), já nos países da União Europeia chega a ser 1500 gramas/hab. ano (BNET, 2011). Esta diferença é causada pelo fato de que, nos países europeus, o consumo de abacate vai além da forma in natura, é principalmente na forma de salada; além disso, os benefícios da fruta são mais difundidos do que no Brasil. $O$ abacate ainda sofre uma barreira para o aumento no seu consumo, por se tratar de uma fruta rica em gordura monoinsaturada, os consumidores criam uma imagem de que é uma fruta gordurosa, porém por ser monoinsaturada, não deixa os níveis de colesterol se elevar no sangue, uma alimentação a base da fruta pode aumentar as taxas de HDL (colesterol bom) e diminuir o colesterol total.

A cada vez mais, os benefícios de uma alimentação à base de abacate são difundidos para a população, principalmente para países europeus e americanos e um 
pouco menos para o Brasil, o motivo é pelo aumento da expectativa de vida; a preocupação pela saúde alimentar e doenças cardiovasculares. Essa repercussão pode causar impactos positivos para a produção de abacate no Brasil, já que o mesmo é o quinto maior produtor mundial de abacate.

Uma pesquisa realizada pela Universidade Estadual do Maranhão, no ano de 2008, apresentou o perfil do consumidor de frutas, admitiu-se o mesmo perfil para o consumidor de abacate, já que as diferenças entre ambos são relativamente baixas. Foram mensurados aspectos como: faixa etária, gênero, composição da família, grau de escolaridade, renda, motivo de consumo, local de preferência para compra, frequência de consumo, dentre outros. Pode-se perceber que a faixa etária dos consumidores compreende-se entre 18 e 35 anos, sendo que a maioria é do sexo feminino. A composição da família é composta entre 4 a 6 pessoas. A renda mensal desses consumidores é em média de 2,5 salários mínimos. Mais da metade dos consumidores afirmam consumir frutas todos os dias. Uma informação importante deste estudo revelou que cerca de $60 \%$ dos consumidores tem interesse em estar informado sobre os benefícios nutricionais das frutas, e, além disso, 48\% gostariam de saber mais sobre tais benefícios que cada fruta oferece aos consumidores. Isso representa uma abertura no mercado de frutas, e, consequentemente um aumento na demanda especificamente de abacate, considerando seus diversos benefícios para a saúde e o interesse dos consumidores em relação ao mesmo.

Em se tratando de frutas orgânicas, a faixa etária do perfil deste consumidor compreende-se entre 30 a 40 anos de idade, demonstrando que o consumidor de idade "madura", por possuir mais experiência, tem mais consciência de uma alimentação saudável. O gênero predominante destes consumidores era feminino, o que demonstra que o ato de compra, ainda concentra-se nas mãos das mulheres. Foi observada também que mais da metade dos consumidores possuem ensino superior completo, demonstrando alto grau de escolaridade e consequentemente domínio sobre as informações. A renda dos consumidores fica concentrada entre 10 a 12 salários mínimos; demonstrando que o consumo de frutas orgânicas está atribuído a pessoas com maior poder aquisitivo. Porém, o conceito de orgânicos ainda é visto 
como algo periférico entre os consumidores e é preciso mais esforço do varejo alimentar para inserir de vez esse tipo de produto no hábito de compra da população.

A elasticidade-renda da demanda não é afetada para diversas faixas de renda, ou seja, um aumento na renda desses consumidores não irá influenciar no aumento do consumo de abacates, por existirem outras frutas disponíveis no mercado que podem satisfazer as necessidades nutricionais dos consumidores, da mesma forma que o abacate, a função renda não irá afetar diretamente o consumo.

$\mathrm{O}$ consumo de abacate no Brasil é de $0,301 \mathrm{~kg} / \mathrm{hab}$. ano. A Figura 8 apresenta a evolução deste consumo no Brasil, em seguida a Figura 9 demonstra a evolução do consumo nas grandes regiões do Brasil.

Figura 8: Evolução do consumo per capita de abacate no Brasil

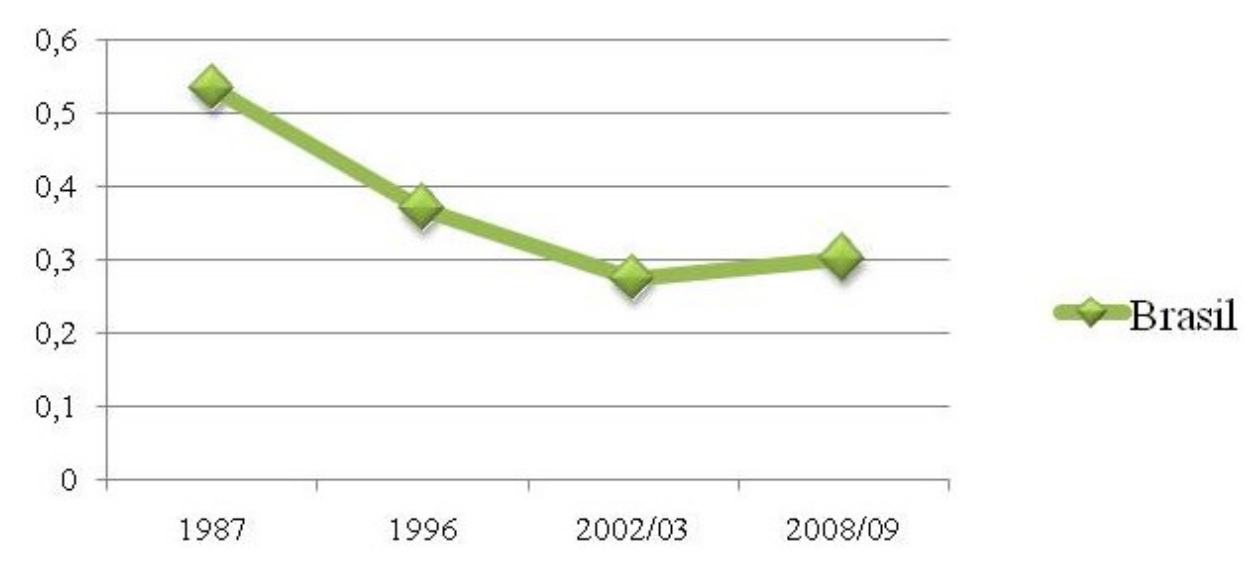

Fonte: ELABORADA PELOS AUTORES COM BASE NOS DADOS DO IBGE.

Figura 9: Evolução do consumo per capita de abacate por região do Brasil 


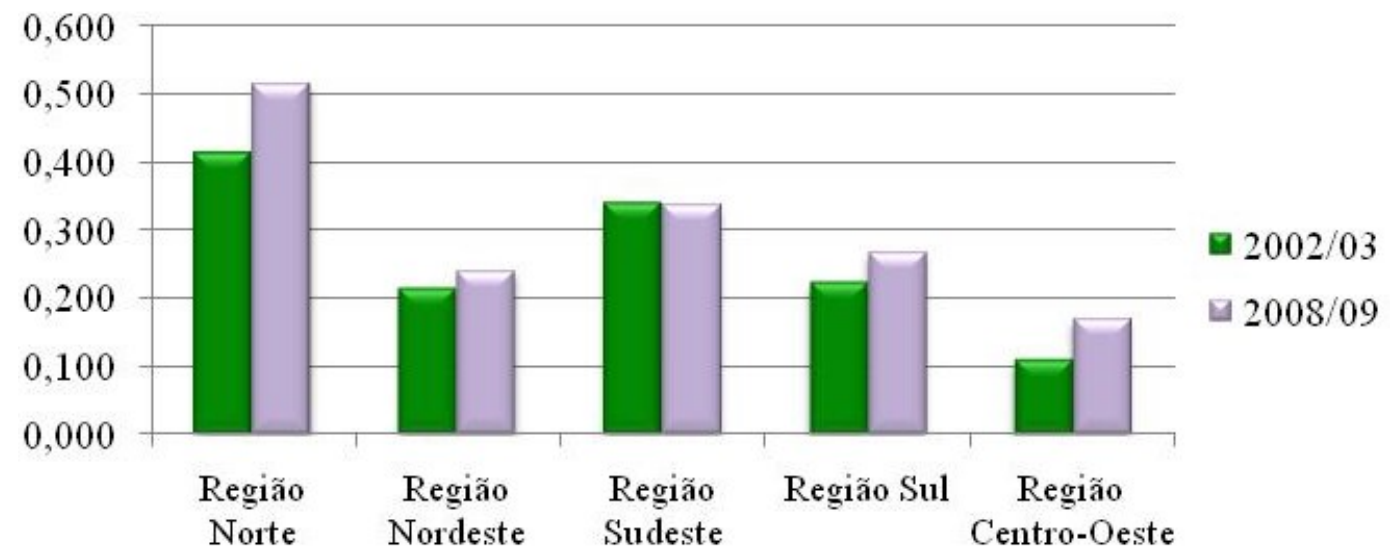

Fonte: ELABORADA PELOS AUTORES COM BASE NOS DADOS DO IBGE.

\section{CONCLUSÃO}

A produção brasileira se encontra em decrescimento, em análise, o mesmo vem acontecendo com a produção da região da alta paulista, em função do fortalecimento da cultura canavieira e de amendoim na região.

A demanda da fruta entre os brasileiros é baixa se comparada com países europeus, com consumo médio de 301 gramas por pessoa/ano, contra 1500 gramas por pessoa/ano consumido pelos europeus, que tem o hábito de consumi-la além da forma in natura, na forma de salada. Além também de seus benefícios serem menos difundidos aqui no Brasil e possuir uma imagem de fruta gordurosa, no entanto, pelo fato de ser monoinsaturada, contribui para regular o nível de colesterol no sangue e glicemias para pessoas com diabetes.

$O$ perfil dos consumidores se manteve 0 mesmo em relação aos consumidores de fruta em geral. Já se tratando de frutas orgânicas, o perfil de consumo, tem compreendido entre 30 a 40 anos, com alto grau de escolaridade, além de ter maior poder aquisitivo e consequentemente possuindo o domínio da informação, demonstrando maior preocupação com uma alimentação saudável.

\section{REFERÊNCIAS}


AGRIANUAL. Fundação Nacional da Pecuária. 13a edição. Local de publicação: São Paulo. FNP, 2008. p.143-147.

BARBIERI, José Carlos; SIMANTOB, Moysés Alberto. Organizações Inovadoras Sustentáveis. São Paulo. Editora Atlas, 2007. p.3.

BNET. Research and Markets: Avocado Consumption in the European Union has Increased Significantly over the Last Ten Years. Disponível em:

<http://findarticles.com/p/articles/mi_m0EIN/is_2005_August_4/ai_n14862320/> Data de acesso: set 2011.

CAMPESTRE INDÚSTRIA E COMÉRCIO DE ÓLEOS VEGETAIS. Óleo de abacate. Disponível em: <http://www.campestre.com.br/oleo-de-abacate.shtml> Data de acesso 25 mar 2009.

DORNELAS, José. Análise de Mercado. Disponível em:

<http://www.planodenegocios.com.br/www/index.php/informcao/2960-como-fazer-a-analise-demercado-do-seu-plano-de-negocios> Data de acesso set 2011.

FAO. Disponível em <http://www.fao.org/> Acessado em 22 de setembro de 2014

FRANCISCO, Vera Lúcia Ferraz dos Santos; BAPTISTELLA, Celma da Silva Lago. Cultura do abacate no estado de São Paulo. Diponível em: < http://www.iea.sp.gov.br/out/publicacoes/pdf/tec30505.pdf> Data de acesso 25 mar 2009.

MATTAR, Igor Cesar Cardoso. Exportação de Frutas Brasileiras Para a Comunidade Européia. Um Estudo de Caso. Universidade Estadual do Paraná. Curitiba, 2005. Disponível em:

<http://pt.scribd.com/doc/56745134/6/PERFIL-DO-MERCADO-CONSUMIDOR-EUROPEU> Data de acesso: set 2011.

NOSSO CAMPO. Produtores de Tupã criam um novo tipo de abacate e investem na produção. Disponível em: <http://tvtem.globo.com/nossocampo/materia.asp?ID=1481> Data de acesso: 26 mar 2009.

OLIVADO. NUTRIÇÃO NATURAL. About Olivado. Dispovível em: <http://www.olivado.com/about.htm> Data de acesso: 26 maio 2009.

PLANETA ORGÂNICO. Mercado dos Produtos Orgânicos no Mundo. Disponível em: <http://www.planetaorganico.com.br/site/> Data de acesso: set 2011.

TEIXEIRA, C. G. et al. ABACATE: cultura, matéria prima, processamento e aspectos econômicos. $2^{a}$. ed. Série Frutas Tropicais $n^{\circ} 8$, ITAL, Campinas, 1991. 250p.

TRIGO, João Ribeiro; COSTA, Jorge Adelino. Liderança nas organizações educativas: a direção por valores. Disponível em: <http://www.scielo.br/scielo.php?pid=S0104-

40362008000400005\&script=sci_arttext\&tIng=en> Data de acesso: 11 mai 2009. 